\title{
The Rewriting of Native American Myth under Western Context in House Made of Dawn
}

\author{
Ren Jiuju ${ }^{1}$ \\ ${ }^{1}$ Foreign Studies College, Dalian Jiaotong University, Dalian, Liaoning, China \\ renjiuju@126.com

\begin{abstract}
The publishing of House Made of Dawn by contemporary Native American writer Scott Momaday has aroused wide attention on Native American literature from American society. Momaday for the first time revealed the down-to-earth life of Native Americans to the American mainstream world. In House Made of Dawn Momaday rewrote the Navajo and Pueblo myths "war gods" and "stricken twins" in a way that on one hand accorded with the Native American story telling mode and reflect the firm belief of native Americans in their own culture; on the other hand departed from the traditional story telling mode to reflect the collision and conflict, integration and balance between mainstream culture and native American culture.
\end{abstract}

Keywords: House Made of Dawn; western context; Native American myth prototype

\section{西方语境下的印第安故事 \\ ---论《黎明之屋》的印第安神话原型书写}

\author{
任九菊 $^{1}$
}

${ }^{1}$ 大连交通大学外国语学院, 大连, 辽宁, 中国

renjiuju@126.com

摘要

当代美国印第安作家斯科特 - 莫马迪的《黎明之屋》的发表引起了美国社会对印第安文学的关注, 莫马迪对印 第安人的描写也第一次向白人主流社会呈现了印第安人的真实生活状态, 开创了非主流印第安文学的先河。莫 马迪对印第安神话原型 “战神兄弟” 和 “受困兄弟” 在西方语境下的重新书写, 时而符合, 时而跨出印第安传 统故事的模式, 有力突显了印第安文化与白人主流文化的碰撞与冲突, 融合与平衡, 及印第安群体在物质文明 社会中对本族文化的坚守。

关键词: 《黎明之屋》; 西方语境; 印第安神话原型

\section{1. 前言}

《黎明之屋》是 1969 年的普利策获奖作品, 其 作者斯科特・莫马迪也因该作品成为了获得该项殊荣 的第一位印第安作家。莫马迪在《黎明之屋》中对印 第安人和印第安文化的书写开创了客观描述当代印
第安人形象的先河。在此之前, 西方主流文学中白人 作家笔下的印第安人往往是野蛮暴力、神秘论异的野 人形象，而莫马迪第一次为读者呈现出一个有血有肉 的印第安人年轻人在传统部族文化和工业化社会夹 缝中生存的困惑与迷茫。作者莫马迪出生于俄亥俄州 劳顿城, 拥有 $7 / 8$ 的印第安血统, 父亲是画家, 母亲 
是作家, 毕业于新墨西哥州立大学后获得斯坦福大学 博士学位。这样的家庭和教育文化背景, 使莫马迪没 有像多数印第安人那样被困于两种文化无法自拔, 相 反他融入了印第安文化和白人文化这两种文化, 并在 两种文化间游刃有余。

自《黎明之屋》之后, 印第安文学开始受到美国 公众和白人主流文学的关注, 涌现出一批优秀的作 家, 如路易斯 - 厄德里齐、莱斯利 - 希尔科等, 和一 批优秀的印第安文学作品, 如《爱之药》、《典仪》等。 这些作品主要讨论了土地对于印第安人和整个部族 的意义、文化身份的追寻、印第安自我的回归、口述 传统和治疗及传统对现代的影响等主题。这些主题在 《黎明之屋》中也有所体现, 但本文将在这些讨论的 基础上着重研究莫马迪在《黎明之屋》中对于印第安 神话原型在西方语境下的书写。莫马迪对于印第安神 话的改写与重构正体现了了作者对印第安文化和白 人文化本质特征的深刻理解及对两种文化融合、碰撞 的准确把握。

\section{2. 印第安神话原型}

《黎明之屋》主人公所生长的部族深受普韦布 洛、纳瓦霍部族文化影响。小说主人公阿贝尔和他的 哥哥比尔达的形象就来自于普韦布洛的部族故事 “受 困兄弟”。而 “受困兄弟” 则源自于普韦布洛和纳瓦 霍部族的神话原型 “战神兄弟”。普韦布洛和纳瓦霍 文化认为世间万物都是由各种强大的力量组成, 而这 些力量既有恶也有善, 善恶之间总是保持着平衡。如 果平衡被打破, 即使是意外被打破, 厄运和灾难便会 降临。自然界是和谐的, 处于平衡状态的, 打破平衡 的总是人类。“战神兄弟” 所讲述的就是帮助人类 恢复自然平和的故事。“战神兄弟” 是大地之女与太 阳神和水神生下的双胞胎兄弟, 他们长大成人后, 为 了打败给人类带来灾难的怪兽, 历尽艰险寻找父亲, 在众多神明的帮助下, 终于找到父亲并从父亲那里获 得了神力、盔甲和武器, 最后成功击败怪兽, 为民除 害。

“受困兄弟” 以 “战神兄弟”为原型讲述了穷人 家女儿与天神生下的双胞胎兄弟因意外受伤, 被逐出 家门, 之后寻找生父和寻求帮助治疗伤病的故事。“受 困兄弟” 的母亲与天神共度了四个日夜后, 天神离开 了她, 之后她生下了一对双胞胎兄弟。两兄弟长大后 喜欢四处游荡。一次探险中, 他们意外受伤: 哥哥失 明, 弟弟跛脚。家人不愿再养育身有残疾的两兄弟, 便把他们送走。天神一路暗中照顾两兄弟, 并指引他 们来到了圣人住处治疗伤病。但是兄弟俩因不知道应 该给圣人们献上什么贡品, 而遭到圣人的拒绝。后来 圣人发现天神是他们的亲生父亲, 才答应给他们治 疗。然而兄弟俩不熟悉仪典规则，在被告知整个过程 不能出声后, 他们还是因为疼痛而喊出了声音, 第一 次的治疗仪典没有成功。兄弟俩伤心地留下了眼泪, 眼泪化作了歌声, 圣人听到歌声召回了兄弟俩, 治愈 了他们并教会了他们吟唱仪典。两兄弟回到家乡传授
家人治疗仪典, 之后返回和圣人们生活在一起。

“战神兄弟” 和 “受困兄弟” 为这些部族传统故 事模式提供了原型：一个出生便是外来者的主人公, 由于某种原因迫不得已离开家园, 在战胜一系列困 难, 经历一次象征意义上的死亡后, 在灵魂帮助者的 指引下重获新生, 最后重返家园传授自己部族的人民 使他重生的治疗仪典。

\section{3. 西方语境下的印第安故事书写}

西方主流白人文化和印第安文化之间存在着很 大的差异，白人强调个体的作用，个人英雄主义; 印 第安人注重群体, 强调家庭和部族。白人文化重视对 于信息的认知及经济或物质形式的追求，而印第安文 化重视对于智慧的认知及意识的发展和追求。本文将 重点探究作者是如何在主流文学的语境下改写及重 构印第安传统神话原型, 使故事的书写更精准的反应 出两种文化的冲突与融合。

《黎明之屋》讲述的是一个逃离与回归、迷㟠与 觉醒的故事。小说主人公印第安那伐鹤部落的年轻男 子阿贝尔由于无法认同印第安古老仪典，不愿接受传 统文化的束缚而离开了印第安保留地, 参加了第二次 世界大战。战后，他身心俱疲地返回保留地，努力想 让生活回归正轨。他和白人女子安吉拉产生感情, 这 多少慰藉了他战后的迷茫。然而在圣地亚哥节日庆典 举行的斗鸡比赛中, 他由于不熟悉规则而输掉比赛, 继而又被获胜者白化病人胡安袭击。对于部落仪典的 淡忘使阿贝尔最终不甘差辱、恼差成怒酒后用尖刀刺 死了胡安, 他也因此受到了审判和惩罚。出狱后, 他 到洛杉矶的一家印刷厂当装订工，但白人社会中的歧 视和不平等让他无法忍受。于是他带着受伤的身体和 灵魂再一次回到保留地。在陪伴抚养自己长大成人的 外祖父度过生命的最后几天中, 他聆听外祖父讲述古 老的那伐鹤部族故事, 在故事的时空交错, 与自然世 界共融中得到觉悟。之后他将外祖父的遗体留在小屋 中, 在黎明的晨光中开始奔跑, 吟唱那伐鹤族仪典的 长调。

“受困兄弟” 对 “战神兄弟” 故事的继承是全面 的、完整的。它即遵循了分离---启示---回归的故事 模式，又包含了“兄弟” “离家” “寻父” “磨难” “帮 助” “成功” 的元素。而莫马迪对《黎明之屋》的书 写却时而遵循时而脱离, 时而继承时而背离 “受困兄 弟” 的部族故事原型。这种继承与疏离的交融正反应 了印第安文化和白人文化的冲突与融合。

从故事模式来看, 这类故事通常可以看作是关于 主人公心灵成长的故事。这种分离---启示---回归的 模式为主人公积聚力量, 同时表现了深深扎根于部族 文化中的打破禁忌的冒险精神和维护家族及部族的 职责和力量。阿贝尔的故事有时完全符合这一模式, 有时却跨出了这一模式。例如, 阿贝尔没有遇到像“受 困兄弟” 的生父天神那样的特定的心灵帮助者, 向他 揭示宇宙的奥秘和走出困境的方法。但是莫马迪创造 
了在他灵魂之旅中帮助他填补空白的其他形象。当阿 贝尔在洛杉矶被痛打, 几乎就要死去的时候, 故事中 出现了对银汉鱼的 “死亡---重生”之旅的描述，正 好符合阿贝尔当时的状况, 从而为他的恢复提供了力 量。阿贝尔故事的另一点不同是他并没有像 “受困兄 弟” 那样, 反复讲述他的故事, 也没有回到部族, 教 授族人治愈仪典。这些与纳瓦霍原始神话疏离之处正 是作者在西方语境为大家讲述的不同的印第安故事。 他们不但表明了阿贝尔是如何无法完全遵从部族文 化的治疗模式, 也给作者在现代社会的大背景下讲述 一个即溶于又背离了口头传统的故事留有余地。小说 既保证了口头陈述传统的完整性又确保了陈述的真 实性，同时并没有受限于完全重复这类故事的模式。

从故事要素来看, 部族传统故事 “受困兄弟” 的 几个要素 “外来者身份”、“伤病” “离开家乡”、“灵 魂帮助者的指引”、“对仪典的不熟悉而导致治疗的失 败”、“最终治愈” 在阿贝尔的故事中都有对应的体现 或反差。

\section{1. 外来者身份}

与 “受困兄弟” 拥有神秘未知的天神父亲一样, 阿贝尔和比尔达兄弟都是私生子, 没人知道他们的父 亲是谁, 他们的母亲早逝, 由外祖父抚养长大, 他们 从一出生就确定了他们的 “外来者” 身份。而这种 “外 来者” 身份不仅在印第安部族有所体现, 在二战的部 队阿贝尔被戏称为 “族长”, 在洛杉矶的印刷厂, 他 受到白人工友的排挤甚至是毒打, “外来者” 身份一 直伴随着阿贝尔，无处不在。“受困兄弟” 由于外来 者身份遭受族人疏远, 使他们身不由己常常外出游 荡, 寻找他们的父亲, 结果误入黑悬岩受伤。阿贝尔 和比尔达小时候也经常出去游荡, 当他们走进箱型峡 谷的时候, 他们可能不是在找他们的父亲, 但旅途一 样带他们走近了未知的、陌生的土地, 也使阿贝尔从 小就产生了对外面世界的渴望, 成年后最终选择离开 家乡。

\section{2. 伤病}

最初读者很难看出四肢健全、身心健康的少年比 尔达和阿贝尔在身体的病痛上和 “受困兄弟” 中哥哥 的失明和弟弟的跛脚有什么相似之处。但在象征意义 上, 作者生动的表现了比尔达的视而不见和阿贝尔的 行动不便。在两兄弟猎鹅的场景中, 比尔达虽然是行 动的领导者, 是哥哥, 但他很显然没有注意到水鸟从 月光照耀下的河水中飞起是多么的美丽动人。而这 时, 阿贝尔却提醒说 “你看到了吗? 他们太美了”。 在洛杉矶, 阿贝尔被痛打后遍体鳞伤, 一动不动, 这 时他则成了受伤跛脚的弟弟。

\section{3. 离开家乡}

虽然 “受困兄弟” 和阿贝尔都离开了家乡离开了 部族, 但他们离开的动机却不尽相同。前者是被赶走,
后者是主动出走。“受困兄弟” 是在外出游荡后意外 受伤，原本就身份不明再加上身有残疾使“受困兄弟” 受到家庭和族人排挤和嫌弃而被送走; 阿贝尔则是无 法认同部族猎鹰传统, 为寻求自由而离开。在部族猎 鹰活动开始之前, 阿贝尔看到一只雌鹰和一只雄鹰在 天空中朝翔, 他们时而盘旋时而俯冲, 时而紧抓猎物, 时而放掉猎物。在看到这一幕后, 对阿贝尔来说, 这 对猎鹰成了自由、美和生命的象征。在猎鹰活动中阿 贝尔成功地抓获了那只雌鹰, 但此时阿贝尔却无法接 受自由期翔随意控制猎物生死的猎鹰竟然成为别人 的猎物, 任人宰割。与其被人剥夺自由或摇尾乞怜, 阿贝尔宁愿让他有尊严的死去。对于猎鹰传统真正意 义的误解造成了他和部族的疏离, 导致了他的最终离 开。不同于 “受困兄弟” 的另一点是第一次离开归来 后，阿贝尔还有第二次离开。在第一次离开家乡后阿 贝尔加入了战争，与很多士兵一样，他怀揣自由和民 主的梦想，而经历的却是同伴们 “族长” 的嘲讽，目 睹的是人类空前的大屠杀。历经种种苦难, 深受 “民 族”、“光荣”、“牺牲”口号的欺骗，对社会、人生大 感失望和迷惆的阿贝尔回到了保留地, 希望这片养育 他的土地能够帮助他治愈伤痛, 找回人生的目标。然 而离家日久、对于部族传统的淡忘，使他再次做出与 部族文化相背离的错事, 他杀死了在斗鸡比赛中战胜 他而后羞辱他的白化病人胡安。这一举动正体现出了 阿贝尔混沌、迷茫、丧失自我、矛盾冲突的状态。他 即无法融入印第安传统文化，以正确的方式宣泄自己 的愤怒, 也仇视白人社会对他的排挤和嘲讽，在他把 尖刀刺入白化病人胡安体内的时候, 他同样刺入了嘲 讽他为 “族长” 的军队长官体内, 刺入了让他身心俱 疲, 倍感痛苦的白人社会。这一次阿贝尔受到了惩罚, 他被关进了监狱，第二次离开了家乡。

\section{4. 灵魂帮助者的指引}

“受困兄弟” 在被逐出家门寻找父亲的旅途中， “talking god”一直在暗中保护, 并指引他们找到 圣人们的住所, 还暗中帮助他们取得能够换取治疗仪 典的由怪兽看守的珍宝, 献给圣人们, 最后使他们的 病痛得到了治愈。在《黎明之屋》的故事中阿贝尔身 边虽然没有一个像天神一样的特定的、万能的，时刻 保护他、引导他、帮助他摆脱困境的灵魂帮助者，但 可以填补这一空白的其他形象随处可见。在阿贝尔从 战场上回到印第安保留地时, 外祖父弗朗西斯科是帮 助他走出迷惘、重塑自我、回归部族的最好人选，而 阿贝尔在回来的当天喝得酩酊大醉, 竟认不出自己的 外祖父, 从而切断了他与印第安部族的唯一联系。在 阿贝尔输掉斗鸡比赛, 被获胜者胡安差辱后, 他心中 的愤怒本可以通过部族的佩奥特仪典得到宣泄，而他 却选择了杀死胡安。

\section{5. 对仪典的不熟悉而导致治疗的失败和最 终治愈}

打断治疗仪典的主题在受困兄弟和《黎明之屋》 
里都有体现。“受困兄弟” 由于打破禁忌, 在治疗过 程中发出声音而没有完成治疗, 只有从敌人那里夺回 神明的珍宝, 才能继续完成治疗。阿贝尔在被白人工 友打得遍体鳞伤时, 好朋友本为他吟唱有治疗力量的 部族的 “黎明之屋”, 但是阿贝尔并没有立即跟着本 吟唱祷告词, 他在回到部族九天后的黎明才完成了吟 唱。受困兄弟向神明贡献珍宝换取治疗, 阿贝尔在没 有为死去的外祖父穿上漂亮的仪典服装, 并用花粉、 燕麦片、神圣的鹰和火鸡的羽毛为其祝福之前也无法 得到完整的仪典祝福。在两个故事中, 主人公都必须 有意识地创造美和提供爱才能够换取健康。黎明之屋 最后的情景是阿贝尔在黎明中奔跑, 为自己也为比尔 达奔跑。他看到了自己也看到了比尔达。在外祖父死 前的最后一个黎明他小声说出 “阿贝尔和比尔达” 的 名字时, 两兄弟在灵魂上得到了重聚。

\section{4. 结论}

口述传统是印第安文化传承之根基, 印第安神话 又是口述内容之源头, 因此印第安神话原型研究在印 第安文学研究中的地位举足轻重。斯科特 - 莫马迪在 《黎明之屋》中对印第安神话的重新书写, 既生动体 现了当代印第安人群体在白人主流社会中的渴望与 困惑, 矛盾与挣扎, 抗争与妥协, 突显了印第安文化 与白人文化的碰撞与融合; 也表达了在物质文明盛行 的主流社会文化中, 印第安群体在坚守本民族传统文 化的同时, 也要勇于尝试有利于民族发展的新事物。

\section{REFERENCES}

[1] Garcia, S. (1990) Landmarks of Healing---A Study of House Made of Dawn. University of New Mexico Press,New Mexico.

[2] Matthias,S.(1986) N.Scott Momady---The Cultural and Literary Background. University of Oklahoma Press, Norman and London.

[3] Qiu,B.,Zou, H.L.(2011) Recovering Indian identity---Analysis of Momady's House Made of Dawn. Journal of Shenyang University,8: 68-70.

[4] Bi, Y.J. (2009) Thought on the Ecological Philosophy of House Made of Dawn. Journal of Mudanjiang institute of Education, 2: 15-16.

[5] Zou, H.L., Zhang, Y.(2011) Review on the Image of Helpers in Indian Renaissance Novels---take House Made of Dawn, Winter in the Blood and The Ritual as examples. Foreign Languages Research, 5:95-99. 